\title{
QUALITY OF LIFE OF PATIENTS WITH DIABETES MELLITUS TYPES 1 AND 2 FROM A REFERRAL HEALTH CARE CENTER IN MINAS GERAIS, BRAZIL.
}

Adriana Rodrigues da Mata ${ }^{1}$, Juliana Álvares ${ }^{1}$, Leonardo Mauricio Diniz², Michael Ruberson Ribeiro da Silva ${ }^{1}$, Bárbara RodriguesAlvernaz dos Santos ${ }^{1}$, Augusto Afonso Guerra Júnior ${ }^{1}$, Mariangela Leal Cherchiglia ${ }^{2}$, Eli lola Gurgel Andrade ${ }^{2}$, Brian Godman ${ }^{3,4,5 *}$, Francisco de Assis Acurcio ${ }^{1}$

${ }^{1}$ School of Pharmacy, Graduate Program in Medicines and Pharmaceutical Assistance, Federal University of Minas Gerais (UFMG), Avenida Presidente Antônio Carlos, 6627 - Campus

Pampulha, CEP 31270-901, Belo Horizonte, Minas Gerais, Brazil.

${ }^{2}$ School of Medicine, Federal University of Minas Gerais (UFMG), Av. Prof. Alfredo Balena, 190, CEP: $30130-100$, Belo Horizonte, Minas Gerais, Brazil

${ }^{3}$ Strathclyde Institute of Pharmacy and Biomedical Sciences, University of Strathclyde,

Glasgow, UK.

${ }^{4}$ Department of Laboratory Medicine, Division of Clinical Pharmacology, Karolinska Institutet, Karolinska University Hospital Huddinge, SE-141 86, Stockholm, Sweden

${ }^{5}$ Liverpool Health Economics Centre, University of Liverpool Management School, Liverpool, UK.

*Correspondence author: Brian Godman, Department of Laboratory Medicine, Division of Clinical Pharmacology, Karolinska Institutet, Karolinska University Hospital Huddinge, SE-141 86, Stockholm, Sweden. Email: Brian.Godman@ki.se

\begin{abstract}
Quality of life (QoL) characteristics are important in patients with diabetes mellitus (DM 1 and 2). Aim: Evaluate QoL and DM-associated factors among diabetic patients. Methods: Patients attending a University Hospital interviewed about sociodemographic, clinical and QoL characteristics, with QoL measured via the EQ-5D. Descriptive analysis, correlation, linear regression, univariate and multivariate analysis were performed. Results: 346 patients took part, comprising $67 \%$ women, $59 \%$ with DM2, and 32\% DM1. DM 1 patients had a mean QoL of 0.7369 , with retinopathy, depression, dyslipidemia and a serious hypoglycemic crisis significantly reducing QoL. Patients with DM type 2 had mean QoL 0.6582, with hypertension, neuropathy, depression, cancer and dyslipidemia significantly reducing QoL. Reduced QoL also correlated with a lack of physical exercise. Males with both DM1 and 2 had a better QoL. Conclusion: Need for better disease monitoring and control combined with effective activities to improve self-care, reduce complications and improve patients' QoL.
\end{abstract}

\section{Introduction}

Diabetes Mellitus (DM) is a chronic disease and is considered a public health problem across the world. Estimates from the International Diabetes Foundation (IDF) suggest that between 2010 and 2030 , there will be a $69 \%$ increase in numbers of adults with diabetes in developing countries and a $20 \%$ increase in developed countries [1]. By 2035, it is projected that nearly 600 million people worldwide will have diabetes unless addressed, with almost 500 million at risk. Consequently, the population requiring either targeted prevention interventions or diabetes care, including the appropriate use of medicines, could soon exceed 1 billion [2,3,4].

This is relevant as diabetes is a principal cause of death worldwide [4,5], with considerable expenditure on the treatment of diabetes and its complications [1,3]. Diabetes also has a deleterious effect on patients' clinical, social, and economic status as well as their quality of life (QoL) and survival [6,7]. Consequently, it is necessary to seek interventions that facilitate and promote self-care including treatment persistence to address this. It is recognised that a large number of variables including the type of diabetes (DM), use of insulin, age, race, social level, level of education, disease complications, psychological factors, knowledge about the disease, and type of health care may influence the QoL of patients with diabetes [8]. This has implications for future care. Younger age, living with someone, years of education, higher income and better glycemic control are all associated with better QoL [8]. Policies that promote self care should also enhance medication persistence, which can be a concern in these 
patients. Cramer et al found that only $59 \%$ of patients with asymptomatic conditions such as hypertension, diabetes and hypercholesterolaemia took their medication for more than $80 \%$ of their days 'on therapy' in a year [9].

This is important as good patient management will reduce the complications associated with diabetes, including microvascular and macrovascular complications [4,10-13]. Health education, a more active participation of the patient and the patient's family and the rapport between the patient and a multi professional health team are fundamental factors for the patient to acquire knowledge and adhere to their prescribed treatment [8]. Good quality medical care must be based around health care professionals, who have responsibility for patients' quality of care so that they can create an enabling environment for instigating initiatives to improve patient care and reinforce the chances of success and their sustainability [14]. Self-management and decision-making should be major areas of focus to improve patient compliance and persistence, which is a concern in these patients.

With respect to the Qol of patients with diabetes, Jacon et al [15] found that disease complications due to the lack of glycemic control impacted directly on their QoL. The authors also pointed out that the control of DM is not limited to the use of insulin and oral medications. It also requires for instant the patient's discipline to follow a diet and to practice physical exercise. Consequently, patient follow-up is of major importance. Soli et al [16] used the EQ-5D to evaluate how complications may affect QoL in patients with DM types 1 and 2 and also found higher utility values in patients without complications ( 0.90 and 0.85 , respectively), in contrast to the values presented by DM patients with complications at 0.68 and 0.73 , respectively.

Consequently, studies evaluating of the impact of DM on the patients' QoL, especially in the clinic setting, may contribute with relevant information on ways to improve health care policies as well as initiatives to improve the follow-up and QoL of patients with DM. Accordingly, the aim of this study was to evaluate the epidemiologic profile and the factors associated with QoL in patients with DM types 1 and 2 treated at the Endocrinology Department of the University Hospital of the Federal University of Minas Gerais (HC-UFMG), which is a referral unit, within the Brazilian Public health system. Additionally, ascertain the health-state utility (HSU) values of diabetic patients using the EQ-5D-3L based on direct and indirect measures of QoL. The HSU values will be useful for future cost-utility economic evaluations of potential future health care interventions in diabetic patients in Brazil. As a result, this study seeks to contribute relevant information for decision-making and health policy planning.

Within the Brazilian Unified Health System (SUS, from the Portuguese, Sistema Único de Saúde), there is universal access and basic health interventions are carried out within primary and secondary health care institutions. DM2 patients are treated with diet, physical exercise and, if appropriate, oral antidiabetic medicines. Patients who do not obtain control of their diabetes are referred to the tertiary care level, referral center such as the Endocrinology Department of the University Hospital of the Federal University of Minas Gerais (HC-UFMG). In the most severe cases of the disease, i.e. patients without glycemic control affected by comorbidities or complications of diabetes, insulin is administered.

\section{Materials and methods}

In this cross-sectional study, the epidemiological profile and QoL-associated factors were assessed in patients with DM types 1 or 2. Patients who were at least 18 years old, had DM and attended consultations at the Endocrinology Service of University Hospital of the Federal University of Minas Gerais (HC/UFMG) were enrolled in the study. This is the typical place of care for patients with endocrinology and metabolic diseases in Minas Gerais State. In Brazil, the secondary care is undertaken referral centers for specialized diseases when patients need specific attention from medical specialists.

Patients were invited to participate in the study from October 2013 to June 2014. All the participants were informed of the aims of the research and signed 'Terms of Free Informed Consent' forms before answering a questionnaire which contained socioeconomic, demographic, clinical and QoL items. The interviews were performed by Pharmacy 
undergraduate students from the Federal University of Minas Gerais after training in interview procedures, questionnaire application and QoL measurement. QoL was assessed with the EuroQol (EQ-5D-3L) version in Portuguese [17] answered by self-completion by responding patients.

The generic instrument - EuroQol EQ-5D - was chosen for this study in view of its ease of application, the existence of a Portuguese translation validated to populations of both Minas Gerais State and Brazil as a whole, as well as its innovative use in DM patients from a referral health care center.

This generic QoL questionnaire, which gives a single score that is necessary for obtaining measures of utility, is divided in two parts. The first part of the questionnaire is made up of a descriptive system with five health dimensions (mobility, self-care, usual activities, pain/discomfort and anxiety/depression). Each dimension has three levels of response (no problem, some or moderate problems and extreme problems). This part of the instrument allows the participant to describe the gravity of his or her health condition in each dimension. The combination of three different levels of responses for each of the five items gives 243 possible health conditions [18]. The EQ-5D was applied to a Brazilian population sample to define the utility values of each health condition [19]. The second part of the questionnaire contains a visual analogue scale (VAS) from 0 to 100 corresponding, respectively, to the worst and the best imaginable health condition [18].

The sociodemographic (gender, race, age, marital status, level of education, social class) and clinical (disease complications, comorbidities, other diseases) characteristics as well as aspects related to the treatment (number and type of medications used, time since diagnoses) make up the explanatory variables. Social class data were obtained according to the socioeconomic classification criteria of the Brazilian Association of Market Research Companies [20].

Statistical analysis software SPSS version 22.0 was used for frequency and central tendency analysis of the data. Correlation and linear regression analyses were performed to evaluate differences between groups and for multiple comparisons.

The correlation between the measured (VAS) and predicted (descriptive system) QoL of EQ-5D was evaluated with the Pearson correlation test. This test is a measure of the strength and direction of association that exists between two variables measured on at least an interval scale.

Uni- and multivariate linear regression analyses were performed to verify the correlation between the predicted QoL (descriptive system) scores on EQ-5D and the explanatory variables. All variables statistically correlated to the result $(p \leq 0.10)$ in the univariate analysis were included in the multivariate model. The variable deletion method, Backward Method, was used to obtain the final model. The initial and final models were compared using the verisimilitude rate test. The model adequacy was tested with residual analysis. Calculations were performed at confidence level of $95 \%$ and statistical significance of $p \leq 0.05$.

The pharmacotherapeutic follow-up of diabetes mellitus patients in Borges da Costa Infirmary of the Clinic Hospital of the Federal University of Minas Gerais (Project CAAE:

21882813.7.0000.5149) was approved by the Clinical Research Ethics Committee of the Federal University of Minas Gerais. The Informed Consent Form was evaluated and approved for presentation in two copies. This was subsequently read to patients by the researcher, with the patients keeping a copy of the signed form.

\section{Results}

A total of 346 patients were interviewed from October 2013 to June 2014. Application of the full questionnaire lasted on average 20 minutes. Sampling was performed conveniently following the consultation/treatment schedule at the reference health care center. The sample size corresponded to $45 \%$ of the total number of DM patients treated at the clinics in the study period. The sex and DM type profiles of the sample were similar to those of the referral health 
care center generally. Only $15 \%$ of the patients refused participation in the study, $73 \%$ of whom were from the metropolitan region or the countryside and $26 \%$ were male, which was similar to the profile of the participants. Among the reasons given for lack of participation were lack of interest $(47 \%)$, lack of time (33\%) and mobility difficulties (12\%).

Some of the descriptive analysis results including clinical characteristics are presented in Tables 1 and 2.

233 of the participants were female $(67 \%)$ and 242 were not white $(71 \%)$, comprising black, brown, yellow and indigenous groups. 32\% (112) of the participants had DM type 1 and $59 \%$ (205) had DM type 2. The remainder reported they did know whether they had DM 1 or 2 and $1 \%$ reported not to have DM (Table 1 ).

The average age of patients with DM type 1 was 37.53 years $(S D=12.29)$, median 38 years (range: 18 to 78 ). $83 \%$ were between 18 and 49 years, with most patients from social class $\mathrm{C}$ $(57 \%)$, followed by classes $A$ and $B(37 \%)$ and $D$ and $E(6 \%)$. The majority of patients were single $(45 \%)$, followed by married $(32 \%)$, divorced $(10 \%)$, separated $(4 \%)$, cohabited $(4 \%)$ and widowed participants $(3 \%) .66 \%$ had studied for at least eight years. Most of the participants lived in Belo Horizonte (48\%) or in the metropolitan region (36\%). A significant number treated $(16 \%)$ lived in the countryside. The average time since DM diagnosis was 18.20 years (SD = 9,69), median 18.50 years (range: 1 to 44 ). All of the participants took DM-specific medication, $86 \%$ of whom took insulin or analogues and $14 \%$ took oral antidiabetic medication. The average number of medicines used by patients was 4.75 ( $S D=2,968$ ), median 4 (range 1 to 14 ). $57 \%$ of the DM patients were hypertensive and $76 \%$ were obese. Dyslipidemia was observed in 65 $(59 \%)$, who typically took simvastatin. Hypoglycemia in the previous 30 days was reported by $64 \%$. Hospitalization in the previous six months was reported by $18 \%, 8 \%$ of which were related to DM. $40 \%$ reported not having undertook physical exercise in the previous 30 days and $65 \%$ reported adherence to a DM-specific diet.

The average age of patients with DM2 was 55.51 years $(S D=12.29)$, median 56 years (24 to 84). $88 \%$ were between 40 and 79 years, with most patients from social class $C(61 \%)$, followed by classes $A$ and $B(28 \%)$ and $D$ and $E(11 \%)$. Most patients were married $(51 \%)$, followed by single $(22 \%)$, widowed $(14 \%)$, divorced $(5 \%)$, separated $(5 \%)$ and cohabited $(3 \%) .66 \%$ of patients had studied for less than eight years. Most lived in Belo Horizonte $(46 \%)$ or in the metropolitan region (40\%), with $14 \%$ living in the countryside. The average time since DM diagnosis was 12.30 years ( $S D=9.57$ ), median 10 years (range: 0 to 47$)$. All patients took DMspecific medication, $70 \%$ of whom took insulin or analogues combined with oral antidiabetic medication and $39 \%$ had monotherapy. The average number of medicines was 5.92 (SD = 2,876), median 6 (range 1 to 14). $77 \%$ were hypertensive and $57 \%$ were obese. Dyslipidemia was seen in $132(64 \%)$, who typically took simvastatin. Hypoglycemia in the previous 30 days was reported by $30 \%, 21 \%$ of whom needed help, which means that they presented a severe hypoglycemic event. Hospitalization in the previous six months was reported by $22 \%, 6 \%$ of which were related to DM. $42 \%$ reported not having undertook physical exercise in the previous 30 days and $71 \%$ reported adherence to a DM-specific diet. 
Table 1. Socioeconomic, demographic characteristics and type of diabetes mellitus among the patients treated at the endocrinology referral health care center in Belo Horizonte from October 2013 to June 2014

\begin{tabular}{|c|c|c|c|c|c|c|c|}
\hline \multicolumn{2}{|l|}{ Characteristics } & \multicolumn{2}{|c|}{$\begin{array}{l}\text { Diabetes } \\
\text { Type } 1\end{array}$} & \multicolumn{2}{|c|}{$\begin{array}{l}\text { Diabetes } \\
\text { Type } 2\end{array}$} & \multicolumn{2}{|c|}{ Total $^{\star \star \star *}$} \\
\hline & & $\mathbf{N}$ & $\%$ & $\mathbf{N}$ & $\%$ & $\mathbf{N}$ & $\%$ \\
\hline \multirow{3}{*}{ Sex } & Male & 37 & 33 & 64 & 31 & 113 & 33 \\
\hline & Female & 75 & 67 & 141 & 69 & 233 & 67 \\
\hline & Total & 112 & 100 & 205 & 100 & 346 & 100 \\
\hline \multirow{3}{*}{ Race } & White & 38 & 34 & 54 & 27 & 100 & 29 \\
\hline & Non-white* & 73 & 66 & 149 & 73 & 242 & 71 \\
\hline & Total & 111 & 100 & 203 & 100 & 342 & 100 \\
\hline \multirow{7}{*}{$\begin{array}{l}\text { Marital } \\
\text { Status }\end{array}$} & Married & 35 & 32 & 101 & 51 & 149 & 44 \\
\hline & Cohabiting & 7 & 6 & 7 & 3 & 15 & 5 \\
\hline & Single & 49 & 45 & 44 & 22 & 102 & 30 \\
\hline & Separated & 4 & 4 & 10 & 5 & 14 & 4 \\
\hline & Divorced & 11 & 10 & 10 & 5 & 25 & 7 \\
\hline & Widowed & 3 & 3 & 28 & 14 & 33 & 10 \\
\hline & Total & 109 & 100 & 200 & 100 & 338 & 100 \\
\hline \multirow{3}{*}{ Level of education } & $\begin{array}{l}\text { At least } 8 \text { years of } \\
\text { education }\end{array}$ & 74 & 66 & 69 & 34 & 237 & 68 \\
\hline & $\begin{array}{l}\text { Less than } 8 \text { years of } \\
\text { education }\end{array}$ & 38 & 34 & 134 & 66 & 107 & 32 \\
\hline & Total & 112 & 100 & 203 & 100 & 344 & 100 \\
\hline \multirow{4}{*}{ Economic class ${ }^{* * *}$} & $A$ and $B$ & 41 & 37 & 58 & 28 & 218 & 63 \\
\hline & C & 64 & 57 & 124 & 61 & 122 & 35 \\
\hline & $\mathrm{D}$ and $\mathrm{E}$ & 7 & 6 & 22 & 11 & 6 & 2 \\
\hline & Total & 112 & 100 & 204 & 100 & 346 & 100 \\
\hline \multirow{4}{*}{ Place of residence } & Belo Horizonte & 53 & 48 & 92 & 46 & 153 & 45 \\
\hline & Metropolitan region & 39 & 36 & 81 & 40 & 130 & 38 \\
\hline & $\begin{array}{l}\text { Outside the } \\
\text { metropolitan region }\end{array}$ & 18 & 16 & 29 & 14 & 56 & 17 \\
\hline & Total & 110 & 100 & 202 & 100 & 339 & 100 \\
\hline
\end{tabular}

NB: * Category Non-white comprises black, brown, yellow and native Brazilian; ${ }^{* *}$ Marital status "Others" corresponded to $1 \%$; ${ }^{* * *} \mathrm{~A}=$ best economic conditions and $\mathrm{F}$ the worst economic condition according to ABEP, 2014 ( $F$ not seen in this study). ${ }^{* * * *}$ Total of number the patients interviewed included those who did not know if they had DM and those who say they do not have DM.

Table 2 includes the clinical characteristics of the patients, again broken down into DM1 and DM2. 
Table 2. Clinical characteristics of the diabetes mellitus patients treated at the endocrinology referral health care center in Belo Horizonte from October 2013 to June 2014.



NB: DM - diabetes mellitus, AD - antidiabetic. ${ }^{*}$ Diagnosis of. ${ }^{* *}$ Total of number the patients interviewed, included those who don't know if they have DM and those who say they do not have DM. 
Analysis of the EQ-5D descriptive system in patients with DM1 (Table 3) showed that 22\% of patients had a perfect health condition (11111), followed by 11122 and $11121(13 \%)$ and 11112 (11\%); other health conditions appeared in smaller proportions and the worst health condition (33333) was not seen. Moderate problems impacting on QoL related to the dimensions of pain/discomfort (50\%), anxiety/depression (40\%), mobility (23\%) and usual activities $(22 \%)$. The self-care dimension affected the smallest number of patients (8\%). The QoL measure calculated based on the preferences of the general Brazilian population with the EQ-5D descriptive system showed a moderate correlation $(0.240 ; p=0.011)$ with the VAS direct measure. The mean VAS was $72.14(\mathrm{SD}=21.021)$ and median 80 (range: 0 to 100). Utility values obtained for this Brazilian population ranged from 0.164 to 1.0 , with a mean utility of $0.73687(S D=0.1900)$ and median of 0.7370 . After stratification of the indirect QoL measures for the sex of patients, we found 0.7905 and 0.7104 for males and females, respectively, with a significant difference at 95\% confidence level $(p=0.035)$.

Analysis of the EQ-5D descriptive system in patients with DM2 (Table 3) showed that $14 \%$ of patients had perfect health condition (11111), followed by $11122(12 \%), 11121(8 \%), 11112$ (6\%), $21222(6 \%), 21121(5 \%)$ and 21122 (5\%); other health conditions appeared in smaller proportions and the worst health condition (33333) was again not seen. Moderate problems impacting on QoL related to the dimensions of pain/discomfort (56\%), anxiety/depression $(47 \%)$, mobility $(45 \%)$ and usual activities $(33 \%)$. The self-care dimension affected the smallest number of participants $(10 \%)$. The QoL measure calculated based on the preferences of the general Brazilian population with the EQ-5D descriptive system showed a moderate correlation $(0.431 ; p=0.000)$ with the VAS direct measure. The mean VAS was $68(S D=18.990)$ and median 70 (range: 0 to 100). Utility values for this Brazilian population ranged from 0.137 to 1.0 , with a mean utility of $0.65817(S D=0.2020)$ and median of 0.6670 . After stratification of the indirect QoL measures for the sex of patients, we found 0.71013 and 0.63459 for males and females, respectively, with a significant difference at $95 \%$ confidence level $(p=0.013)$.

Table 3. EQ-5D scores of patients with diabetes mellitus treated at the endocrinology referral health care center in Belo Horizonte from October 2013 to June 2014.

\begin{tabular}{|c|c|c|c|c|c|c|}
\hline \multicolumn{2}{|c|}{ QoL Scores } & $\mathbf{N}$ & \multicolumn{2}{|c|}{ Mean } & \multicolumn{2}{|c|}{ Standard Deviation } \\
\hline \multirow{2}{*}{\multicolumn{2}{|c|}{$\begin{array}{l}\text { Indirect } \mathrm{QoL}^{\mathrm{a}}-\text { Diabetes } \mathrm{T}^{*} \\
\text { Indirect } \mathrm{QL}^{\mathrm{a}}-\text { Diabetes } \mathrm{T} 2^{* *}\end{array}$}} & 112 & \multirow{2}{*}{\multicolumn{2}{|c|}{$\begin{array}{l}0,73687 \\
0.65817\end{array}$}} & \multirow{2}{*}{\multicolumn{2}{|c|}{$\begin{array}{l}0,1900 \\
0.2020\end{array}$}} \\
\hline & & 205 & & & & \\
\hline & \multicolumn{3}{|c|}{ Diabetes T1* } & \multicolumn{3}{|c|}{ Diabetes T2** $^{* *}$} \\
\hline $\begin{array}{c}\text { EQ-5D } \\
\text { Dimensions*** }\end{array}$ & & $\mathbf{N}$ & $\%$ & & $\mathbf{N}$ & $\%$ \\
\hline \multirow{3}{*}{ Mobility } & 1 & 85 & 76 & 1 & 111 & 54 \\
\hline & 2 & 26 & 23 & 2 & 92 & 45 \\
\hline & 3 & 1 & 1 & 3 & 2 & 1 \\
\hline \multirow{3}{*}{ Self-care } & 1 & 103 & 92 & 1 & 183 & 89 \\
\hline & 2 & 9 & 8 & 2 & 20 & 10 \\
\hline & 3 & 0 & 0 & 3 & 2 & 1 \\
\hline \multirow{3}{*}{ Usual activities } & 1 & 86 & 77 & 1 & 131 & 64 \\
\hline & 2 & 25 & 22 & 2 & 67 & 33 \\
\hline & 3 & 1 & 1 & 3 & 7 & 3 \\
\hline \multirow{3}{*}{ Pain or discomfort } & 1 & 46 & 41 & 1 & 52 & 25 \\
\hline & 2 & 56 & 50 & 2 & 114 & 56 \\
\hline & 3 & 10 & 9 & 3 & 39 & 19 \\
\hline \multirow{3}{*}{ Anxiety or depression } & 1 & 47 & 42 & 1 & 77 & 38 \\
\hline & 2 & 45 & 40 & 2 & 97 & 47 \\
\hline & 3 & 20 & 18 & 3 & 31 & 15 \\
\hline
\end{tabular}

NB: * Diabetes mellitus Type 1 ; ${ }^{* *}$ Diabetes mellitus Type $2 ;{ }^{* * *} 1$ = no problem, 2 = moderate

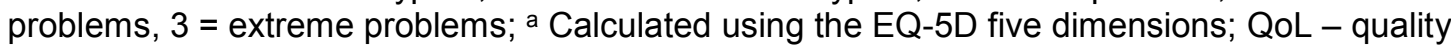
of life. 
When stratifying the analysis by gender, males had significantly $(p=0.035)$ higher mean Qol $(0.79046 \pm 0.1751)$ than females $(0.71043 \pm 0.19259)$. The same was seen for mean VAS values $(p=0.000)$, with males at $81.97 \pm 14.082$ and females at $67.23 \pm 22.24$. In stratified analysis by gender and age, these values were higher for men, but no significant difference between age groups $(p>0.05)$.

ANOVA and multivariate correlation analyses indicated 20 significant explanatory variables $(p<0.10)$ for the indirect $Q o L$ measure. After the sequential deletion of non-significant variables, the final model for the EQ-5D descriptive model for DM1 and 2 are presented in Table 4. The model for DM 1 showed that retinopathy, depression, dyslipidemia diagnosed and serious hypoglycemic crisis significantly reduced QoL $(p<0.05)$. The model for DM2 showed that hypertension, neuropathy, depression, cancer and dyslipidemia significantly reduced ptients' QoL $(p<0.05)$. A reduction in QoL also correlated with lack of physical exercise $(p=0.009)$.

Table 4: Regression analysis of factors associated with quality of life measured with EQ-5D and patients with diabetes mellitus types 1 and 2 treated at the endocrinology referral health care center in Minas Gerais, Brazil, from October 2013 to June 2014.

\begin{tabular}{lccc}
\hline Variables & \multicolumn{3}{c}{ EQ-5D } \\
\hline Diabetes mellitus type 1 & & & \\
\hline Fixed part & Coefficient & $\begin{array}{c}\text { Standard } \\
\text { Deviation }\end{array}$ & p value \\
\hline Constant & 0,885 & 0,030 & 0,000 \\
Retinopathy (yes) & $-0,068$ & 0,034 & 0,048 \\
Depression (yes) & $-0,124$ & 0,035 & 0,001 \\
Dyslipidemia (yes) & $-0,075$ & 0,034 & 0,027 \\
Hypoglycemic crisis (serious) & $-0,038$ & 0,019 & 0,043 \\
\hline Diabetes mellitus type 2 & & & \\
\hline Fixed part & Coefficient & Standard & p value \\
\hline Constant & 0,899 & 0,032 & 0,000 \\
Hypertension (yes) & $-0,072$ & 0,029 & 0,015 \\
Neuropathy (yes) & $-0,122$ & 0,025 & 0,000 \\
Depression (yes) & $-0,089$ & 0,026 & 0,001 \\
Cancer (yes) & $-0,108$ & 0,035 & 0,002 \\
Dyslipidemia (yes) & $-0,061$ & 0,027 & 0,023 \\
Physical Exercise (none) & $-0,066$ & 0,025 & 0,009 \\
\hline
\end{tabular}

\section{Discussion}

The prevailing sociodemographic characteristics: female, not white, classes $B$ and $C$, living with someone, in Belo Horizonte or the metropolitan region, average age of 49 years, mean time of diagnosis of 14 years are very similar to DM patient data obtained with another generic questionnaire reported by Alves et al [21]. Ferreira and Santos [22] evaluated the negative impact of DM on the life of patients and also observed a predominance of females $(71 \%)$, but an average age of 57 years $(S D=10.9)$.

Preventive health habits and care are more familiar to females, which may be associated with the greater frequency of female consultations at this referral health care center. Gomes et al [23] reported that males rarely seek health care due to a predominant model of masculinity. Male characteristics such as invincibility, strength and virility are incompatible with demonstrations of weakness, fear, anxiety and diffidence shown in the search for health care services. Consequently, according to these authors, males are bound by cultural ties that make the adoption of self-care practices more difficult. Furthermore, Alves et al [24] observed that males seek out health care services only in extreme conditions and attributed their low demand to males' being more complacent, irresponsible, living for work, being home supporters, in addition to personal aspects linked to lack of knowledge. However, the Brazilian workforce data do not corroborate the argument that males do not seek health care because they are home providers, as the head of many households at present are females. The greatest QoL value 
observed between males in this study may be explained by the fact that males enjoy better health conditions.

The mean QoL value obtained by indirect measurement with the EQ-5D $(0.6878 \pm 0.0109)$ corresponds to the mean values of the valuation parameters $(-0.235$ to 0.869$)$ found by Andrade et al [25] in the general population of Minas Gerais, which had 5\% DM patients. Males presented lower minimum values than females and a greater standard deviation. However, males also apparently had higher QoL than females, which was also reported by Alves et al [21], as well as in our study.

The QoL measure calculated indirectly, based on the preferences of the general Brazilian population with the EQ-5D descriptive system, had a correlation 0.410 (for patients DM2; $p=0.000$ ) and 0.240 (for patients $\mathrm{DM} 1 ; \mathrm{p}=0.011$ ) with the VAS direct measure of QoL. Alvares et al [26] found a similar value (0.386) using the same questionnaire in renal replacement therapy patients and Sakamaki et al [27] found correlation of 0.331 using EQ5D in patients with type 2 diabetes mellitus in Japan.

The present results show that a diagnosis of hypertension, neuropathy, depression, cancer, dyslipidemia and lack of physical exercises were significantly related to a low QoL for patients with DM2. For DM1 patients, retinopathy, depression, dislipidemia and serious hypoglycemic crisis decreased their QoL (Table 3). This is similar to the findings of Aguiar et al [8]. As mentioned, these authors found evidence that DM type, use of insulin, age and patient race, social and education levels, disease complications, psychological factors, knowledge about the disease, type of care and other factors may influence the QoL of DM patients. Our findings are also similar to Soli et al [16], who using the EQ-5D to evaluate how complications may affect QoL in patients with DM types 1 and 2 . They found higher utility values in patients without complications ( 0.90 and 0.85 , respectively) versus those with complications, 0.68 and 0.73 , respectively. Zhang et al. [28] found a similar mean utility value $(0.80)$ in DM patients using the EQ-5D.

Similarly to Alves et al [21], we also did not find any correlation between QoL and age, marital status and number of years with DM.

Regarding the type of DM medication used, Fal et al [29] reported that patients treated with insulin seemed to have a more stable QoL, to be less susceptible to DM-related factors such as comorbidities, overweight, and others, when compared to patients who used oral hypoglycemic medication. However, no association was found in this study between the type of medication used and QoL.

Regarding risk factors associated with DM, arterial hypertension, obesity and dyslipidemia predominated, which is in agreement with other studies [30-34]. Consequently, there needs to be active management of patients' blood and lipid levels; the latter for instance with $40 \mathrm{mg}$ simvastatin $[10,13]$.

A recent systematic review indicated that depression is negatively associated with QoL in patients with DM type 2. Despite a number of factors negatively related with $D M$, including long term treatment complications and comorbidities with a negative effect on QoL, new research has also proposed a contribution from this psychological factor [35]. Our study supports this finding.

A positive correlation between physical exercise and health-related QoL has also been observed in a study with another generic QoL questionnaire [21]. Similar to our study, lack of physical exercise was associated with a negative effect on QoL. Additional studies should be undertaken to further elucidate this association to provide future guidance.

In our study, the greatest losses of information were detected for questions on the type of DM $(9 \%)$ and "if (the participant) has ever had or presently has HIVIAIDs" (11\%), which may be attributed to prejudice about both diseases. Specifically in the case of DM, lack of knowledge ( $8 \%$ reported not to know whether they had DM) and disease denial (1\%) were seen in this 
study as well as in other studies [36]. There were also many losses regarding current medicines being taken by patients because not everyone interviewed had their prescription with them or remembered all the medicines they were currently prescribed. Consequently, this variable wasn't used in this model.

A greater frequency observed regarding the adoption of a DM-specific diet can be partially related to a social desirability bias. Consequently, we believe patients may have answered the questionnaire according to a socially recommend health style that does not correspond to his or her daily habits.

The EuroQol group recently introduced a new version of the instrument with 5 levels (EQ-5D$5 \mathrm{~L}$ ); however, it has not yet been validated for the Brazilian population. Some countries have already started its evaluation, e.g. Golicki et al [37], and it is likely we will use the updated versions in future studies once validated.

One of the major limitations of this study is that it is cross sectional, and, therefore, does not allow the establishment of a temporal correlation in the determination of causal associations. It also presents information bias, since the data was collected with a questionnaire and the QoL evaluation was done with a generic instrument. Regarding EQ5D, is known that a ceiling effect may occur when a great number of the reported health condition values are high, because faceto-face interviews may enhance the risk of social desirable answers. Patients also reported they had difficulty understanding VAS scores. This may have occurred because of the high level of functional illiteracy (27\%) or the unsatisfactory educational level in Brazil [38].

We acknowledge this study does not have external validity as the studied population is specific and treated at a university referral health care center located in Belo Horizonte. In addition, although patients from Belo Horizonte, the metropolitan region and from the countryside are treated at this center, the population is not representative of the State as a whole. Despite this, internal validity was good and demonstrated by the validation of the questionnaire through its high-quality data reliability and reproducibility for $13 \%$ of the sample. In addition, this study was conducted among a diverse multicultural and socio-economic population adding to the literature in this field and adds to knowledge about the impact of DM on patients' utility, helping with future economic evaluations among the Brazilian population.

The originality of this study is in the evaluation of QoL in DM patients treated in routine clinical care at a referral health care center run by a well-qualified team. The study presents the epidemiological profile and quality of life of these patients, contributing to early evaluations of interventions to improve their quality of life. The results show that most of the DM patients present with a large number of associated comorbidities and low QoL scores. These data can be useful in future economic evaluations evaluating different treatment approaches, including new interventions, among SUS patients with DM. Ensuring access to ambulatory and hospital care as well as access to medicines is essential in managing this chronic disease, but may not be sufficient to appreciably improve their health condition. Specific studies on the quality of the use of medicines and their impact on utility and cost-utility, e.g. cost per quality adjusted life years, should be performed in the real world in order to better understanding DM as a health condition and its optimal management. This will be the subject of future research with our patients.

\section{Key messages:}

- The incidence and prevalence of diabetes is increasing and represents a major world-wide health problem in terms of its morbidity and associated negative impact on patients' qualityof-life, mortality and associated costs

- However, the treatment of patients with diabetes, bringing the patient's metabolic state as close as possible to the normal physiology, is not easily achieved. As s result, requiring the patient's and the family's understanding and efforts to address this

- Consequently, evaluating the epidemiologic profile and the factors associated with QoL in patients with diabetes could contribute to the design of interventions aiming at effective self- 
care, promotion of the quality of use of medicines and improved individual and collective health conditions

- The mean QoL of patients with Type 1 and $2 \mathrm{DM}$ attending the Endocrinology Department of the University Hospital of the Federal University of Minas Gerais (HC-UFMG) was 0.6878 $(S D=0.0109)$ using the EuroQol questionnaire $(E Q-5 D)$. The mean QoL was lower in DM2 patients

- Multivariate analysis showed that having a diagnosis of neuropathy, depression, cancer, blindness and dyslipidemia significantly $(p<0.05)$ decreased QoL

- Multiple medications $(p<=0.001)$ and the lack of physical activity $(p=0.028)$ also decreased patients' QoL. Male gender was associated with better QoL $(p=0.016)$

- The findings indicate a need to further implement educational measures regarding health conditions, the importance of the treatment and its persistence, as well as the need of effective self-care as early as possible to reduce complications and improve the QoL of patients.

\section{Acknowledgements and conflicts of interest}

Fundação de Amparo a Pesquisa do Estado de Minas Gerais - FAPEMIG (Process No. PPM00182-13).

We wish to thank the Endocrinology Service in Borges da Costa Infirmary of the Clinic Hospital of the Federal University of Minas Gerais and the patients, clinical staff and residents, nursery and front desk staff and the staff of the Brazilian Longitudinal Study of Adult Health (ELSA Brasil) for their help and support. Thanks also go to the Research Project fellow and students from the Pharmacology College of the Federal University of Minas Gerais who actively participated in this project and the Medication and Pharmaceutical Support Graduate Course of the Pharmacology course of the Federal University of Minas Gerais.

We also wish to thank the EuroQol group for permitting the use of the EQ-5D instrument for this study and for providing the locally validated language versions of the instrument.

The write-up was in part supported by a Newton Advanced Fellowship awarded to Professor Augusto Afonso Guerra Junior by the Academy of Medical Sciences, through the UK Government's Newton Fund programme

The authors have no other conflicts of interest to declare.

\section{References}

1. Shaw JE, Sicree RA, Zimmet PZ. Global estimates of the prevalence of diabetes for 2010 and 2030. Diabetes research and clinical practice. 2010;87(1):4-14.

2. International Diabetes Federation. IDF Diabetes Atlas, 6th edn. Brussels, Belgium. Available at URL: http://www.idf.org/sites/default/files/EN_6E_Atlas_Full_0.pdf2013 (Accessed 15 September 2015)

3. WHO. Access to new medicines in Europe: technical review of policy initiatives and opportunities for collaboration and research. Available at URL:

http://www.euro.who.int/en/health-topics/Health-systems/medicines/publications2/2015/accessto-new-medicines-in-europe-technical-review-of-policy-initiatives-and-opportunities-forcollaboration-and-research (Accessed 15 September 2015)

4. WHO. Global Status Report on noncommunicable diseases - 2014. Available at URL: http://apps.who.int/iris/bitstream/10665/148114/1/9789241564854_eng.pdf (Accessed 20 September 2015)

5. Godman B, Malmstrom RE, Diogene E, Gray A, Jayathissa S, Timoney A, et al. Are new models needed to optimize the utilization of new medicines to sustain healthcare systems? Expert review of clinical pharmacology. 2015;8(1):77-94.

6. Sociedade Brasileira de Diabetes - SBD (2014). Diretrizes da Sociedade Brasileira de Diabetes: 2013-2014. Sociedade Brasileira de Diabetes; [organização José Egidio Paulo de Oliveira, Sérgio Vencio]. São Paulo: AC Farmacêutica, 2014. 382p. Available at URL: http://www.diabetes.org.br/images/pdf/diretrizes-sbd.pdf. Accessed 16 June 2014. 
7. Santos Filho CV, RODRIGUES WHC., SANTOS RB. (2008) Emotional factors, life quality and adhesion of treatment in adult with diabetes type 2. Esc Anna Nery Rev Enferm.; 12 (1): 125 - 129. http://www.scielo.br/pdf/ean/v12n1/v12n1a19.pdf. Accessed 13 June 2013.

8. Brasil, F. P. S. (2009) Efeitos da apresentação de material educativo para pacientes com diabetes tipo 2 sobre o conhecimento da enfermidade e a adesão ao tratamento. [Dissertação de mestrado em processos de desenvolvimento humano e saúde, área de concentração saúde-doença, apresentada ao Instituto de Psicologia da Universidade de Brasília. Brasília: Universidade de Brasília, $95 \mathrm{p}$.

9. Cramer JA, Benedict A, Muszbek N, Keskinaslan A, Khan ZM. The significance of compliance and persistence in the treatment of diabetes, hypertension and dyslipidaemia: a review. International journal of clinical practice. 2008;62(1):76-87.

10. Tight blood pressure control and risk of macrovascular and microvascular complications in type 2 diabetes: UKPDS 38. UK Prospective Diabetes Study Group. BMJ. 1998;317(7160):70311. Tandon N, Ali MK, Narayan KM. Pharmacologic prevention of microvascular and macrovascular complications in diabetes mellitus: implications of the results of recent clinical trials in type 2 diabetes. American journal of cardiovascular drugs : drugs, devices, and other interventions. 2012;12(1):7-22.

12. Effect of intensive blood-glucose control with metformin on complications in overweight patients with type 2 diabetes (UKPDS 34). UK Prospective Diabetes Study (UKPDS) Group. Lancet. 1998;352(9131):854-65.

13. Collins R, Armitage J, Parish S, Sleigh P, Peto R. MRC/BHF Heart Protection Study of cholesterol-lowering with simvastatin in 5963 people with diabetes: a randomised placebocontrolled trial. Lancet. 2003;361(9374):2005-16.

14. WHO. Quality of care: a process for making strategic choices in health systems. 2006. France: WHO Library. 50p.

15. Jacon T, Baier L, Garabeli AA, Benetoli A, Daher JB. (2013) Aplicação do questionário de qualidade de vida DQOL-Brasil a pacientes portadores de diabetes mellitus tipo 2 na Unidade Básica de Saúde Nilton Luiz de Castro - Ponta Grossa -PR. In: $11^{\circ}$ Encontro Conversando Sobre Extensão Na Universidade Estadual De Ponta Grossa (UEPG) - CONEX. Vol. 11, 2013, Ponta Grossa: UEPG. 2013, 6p. Available at URL:

http://www.uepg.br/proex/anais/trabalhos/11/Comunica\%C3\%A7\%C3\%A30\%20Oral/Oral\%20(1 37).pdf. Accessed 21 October 2014.

16. Soli O, Stavem K, Kristansen IS (2010) Health-related quality of life in diabetes: the associations of complications with EQ-5D scores. Health and Quality of Life Outcomes. 2010, $8: 1-8$

17. The EuroQol Group (1990). EuroQol-a new facility for the measurement of health-related quality of life. Health Policy 16(3):199-208. In: EQ-5D-3L user guide. 2015. Referring to the EQ5D-3L instrument in publications. Version 5.1. April 2015.

18. The Euroqol Group. Reenen M. van; Mark Oppe. (2015). EQ-5D-3L user guide. Basic information on how to use the EQ-5D-3L instrument. EuroQol Group Executive Office. On behalf of the EuroQol Group. The Netherlands: EuroQol Group 2015, Version 5.1, April 2015. http://www.euroqol.org/fileadmin/user_upload/Documenten/PDF/Folders_Flyers/EQ-5D3L_UserGuide_2015.pdf. Accessed 01 May 2015

19. Santos M, Cintra MACT, Monteiro AL, Santos B, Gusmão Filho F, Andrade MV et al. Brazilian valuation of EQ-5D-3L health states: Results from a saturation study. Medical Decision Making (accepted - in press). 2015.

20. Associação Brasileira de Empresas de Pesquisa - ABEP (2014). Publicações: códigos e guias. Critério de classificação econômica Brasil. 2014.

http://www.abep.org/new/codigosCondutas.aspx. Accessed 10 January 2014.

21. Alves TOS, Souza SA, Souza CSS, Gois CFL, Guimarães AMDN, Mattos MCT (2013). Health-related quality of life of people with diabetes mellitus. Revista Mineira de Enfermagem. jan/mar, 17(1): 135-140.

22. Ferreira FS, Santos C B (2009) Health-related quality of life of diabetic patients seen by family health team. Revista Enfermagem UERJ, Rio de Janeiro, jul/set; 17(3): 406-11.

23. Gomes R, Nascimento E F, Araújo FC (2007) Why do men use health services less than women? Explanations by men with low versus higher education. Cadernos de Saúde Pública, Rio de Janeiro, 23(3):565-574, mar. Available at URL:

http://www.scielo.br/scielo.php?script=sci arttext\&pid=S0102-311X2007000300015. Accessed 15 July 2014. 
24. Alves AF, Silva RP, Ernesto MV, Lima AGB, Souza FM (2011). Gênero e saúde: o cuidar do homem em debate. Psicologia: Teoria e Prática, 13(3):152-166.

25. Andrade MV, Noronha KVMS, Maia AC, Kind P. (2013). What matters most? Evidencebased findings of health dimensions affecting the societal preferences for EQ-5D health states. Caderno Saúde Pública. Rio de Janeiro, 29 Sup.: S59-S72.

26. Alvares J, Almeida AM, Szuster DAC, Gomes IC, Andrade EIG, Acurcio FA, Cherchiglia ML. (2013). Factors associated with quality of life in patients in renal replacement therapy in Brazil. Ciência \& Saúde Coletiva, 18 (7):1903-1910.

27. Sakamaki H, Ikeda S, Ikegami N, Uchigata Y, Iwamoto Y, Origasa Y, Otani T, Otani Y. (2006). Measurement of HRQL Using EQ-5D in Patients with Type 2 Diabetes Mellitus in Japan. International Society for Pharmacoeconomics and Outcomes Research (ISPOR), 1098-3015 (06): 47-53.

28. Zhang P, Brown MB, Bilik D, Ackermann RT, Li R, Herman WH. (2012). Health utility scores for people with type 2 diabetes in U.S. managed care health plans. Results from translating research into action for diabetes (TRIAD). Diabetes Care, November, 2012. v. 35, n. 11: 2250 2256. Available at URL: http://care.diabetesjournals.org/content/35/11/2250.full.pdf. Accessed 24 June 2013.

29. Fal AM, Jankowska B, Uchmanowicz I, Sen M, Panaszek B, Polanski J. (2011) Type 2 diabetes quality of life patients treated with insulin and oral hypoglycemic medication. Acta Diabetologica 48: 237-242.

30. Hu FB et al. (2003) Television watching and other sedentary behaviors in relation to risk of obesity and type 2 diabetes mellitus in women. JAMA; 289: 1785-1791.

31. Dunstan DW et al. (2007). Association of television viewing with fasting and 2-h postchallenge plasma glucose levels in adults without diagnosed diabetes. Diabetes Care 30:516 -522, 2007.

32. Brasil. Ministério da Saúde. Secretaria de Vigilância em Saúde (2011). Departamento de Análise de Situação de Saúde. Plano de ações estratégicas para o enfrentamento das doenças crônicas não transmissíveis (DCNT) no Brasil 2011-2022. Ministério da Saúde. Secretaria de Vigilância em Saúde. Departamento de Análise de Situação de Saúde. - Brasília: Ministério da Saúde, 2011. 148 p.: il. - (Série B. Textos Básicos de Saúde). Available at URL: http://189.28.128.100/dab/docs/geral/plano_dcnt.pdf. Accessed 15 January 2013. 33. Fundação Oswaldo Cruz - FIOCRUZ (2012). Instituto de pesquisa aplicada - IPEA, Ministério da Saúde - MS, Secretaria de Assuntos Estratégicos da Presidência da República. A saúde no Brasil em 2030: diretrizes para a prospecção estratégica do sistema de saúde brasileiro. Rio de Janeiro: Fiocruz/ Ipea/ Ministério da Saúde/Secretaria de Assuntos Estratégicos da Presidência da República, 2012. 323 p. Available URL:

http://andromeda.ensp.fiocruz.br/teias/sites/default/files/biblioteca_home/Saude_Brasil_2030.pd f. Accessed 14 January 2014.

34. Xie YJ et al. (2014) Television Viewing Time in Hong Kong Adult Population: Associations with Body Mass Index and Obesity. PLoS ONE 9 (1): e85440.

doi:10.1371/journal.pone.0085440. http://dx.doi.org/10.1371/journal.pone.0085440

35. Ali S, Stone M, Skinner TC, Robertson N, Davies M, Khunti K (2010). The association between depression and health-related quality of life in people with type 2 diabetes: a systematic literature review. Diabetes/Metabolism Research and Reviews. 26: 75-89.

36. Gomes AMT, Silva EMP, Oliveira DC (2011) Representações sociais da AIDS para pessoas que vivem com HIV e suas interfaces cotidianas. Rev. Latino-Am. Enfermagem [Internet]. maiojun; 19(3):[08 telas]. Available at URL: http://www.scielo.br/pdf/rlae/v19n3/pt_06. Accessed 14 May 2014.

37. Golicki D, Niewada M, Buczek J, Karlinska A, Kobayashi A, Janssen MF, et al. (2015). Validity of EQ-5D-5L in stroke. Quality of Life Research, 24:845-850.

38. Instituto Paulo Montenegro - INAF 2012 Indicador de Analfabetismo Funcional 2011. Principais Resultados. São Paulo, 2012. 18p. Available at URL:

http://www.institutocyrela.com.br/site/arquivos/geral/informe_resultados_inaf2011_versaofinal_12072012b.pdf. Accessed 15 July 2014. 